\title{
Fetal Doppler reference values in women with a normal body mass index T Dias ${ }^{1,2}$, S Abeykoon ${ }^{3}$, S Kumarasiri ${ }^{3}$, P Mendis ${ }^{2}$, C Gunawardena ${ }^{3}$, G Pragasan ${ }^{3}$, T Padeniya $^{3}$, A Pathmeswaran ${ }^{2}$
}

(Index words: Umbilical artery pulsatility index (UA PI), Middle cerebral artery pulsatility index (MCA PI), Cerebroplacental ratio (CPR), Body mass index (BMI))

\begin{abstract}
Objectives To construct gestation specific reference limits for fetal umbilical (UA), middle cerebral artery (MCA) pulsatility indices $(\mathrm{PI})$ and the cerebroplacental ratio (CPR) in singleton pregnancies with normal BMI between 16 and 40 weeks of gestation.

Methods We ultrasonographically examined 596 fetuses from women with normal nutritional and health status and minimal environmental constraints on fetal growth. Each mother was considered only once for measurement of fetal Doppler indices, at gestations between 16 and 40 weeks in a prospective cross-sectional study. Gestational age was confirmed by fetal crown-rump length measurement between 11 and 14 weeks. Pulsatility indices of umbilical and middle cerebral arteries were measured by real time and Doppler ultrasonography. CPR ratio was calculated by dividing MCA PI by UA PI. The fetal Doppler measurements obtained from the current study were compared with commonly used reference charts. For each parameter separate polynomial regression models were fitted to estimate the gestation specific means and standard deviations, assuming that the measurements have a normal distribution at each gestational age.
\end{abstract}

Results A significant difference of fetal Doppler indices was observed between our study and previously published reference charts for most gestational weeks. The fitted 10th, 50th and 90th centiles at 40 weeks of gestation were $0.65,0.87$ and 1.08 for UA PI; 0.93, 1.32 and 1.71 MCA PI; 1.02, 1.58 and 2.13 for CPR.

Conclusions These charts can be used for better defining the normal range of fetal arterial Doppler indices. This will be useful in the diagnosis and management of fetuses with abnormal fetal growth.

Ceylon Medical Journal 2019; 64: 59-65

DOI: http://doi.org/10.4038/cmj.v64i2.8888

\section{Introduction}

Sub-optimal growth is recognized as a major risk factor for most of explained and unexplained intra-uterine fetal deaths [1]. Small for gestational age (SGA) where fetal size is below the 10th centile is known to be associated with adverse pregnancy outcomes. SGA is a heterogenous group, consists of fetuses with fetal growth restriction (FGR), fetuses affected with genetic disorder or structural abnormalities and constitutionally small fetuses. Uteroplacental insufficiency is responsible for FGR and carries a higher risk of adverse fetal outcomes but it is only responsible for a proportion of SGA. Antenatal fetal growth assessment is intended to identify the fetuses at risk of FGR [2]. Current evidence suggests that the use of Doppler ultrasound in high-risk pregnancies reduced the risk of perinatal deaths and resulted in less obstetric interventions [3].

Differential fetal growth and Doppler references according to ethnicities have been a matter of continuous discussion. These differences could be genetic or constitutional, supporting the use of customized charts to adjust fetal growth and wellbeing according to each standard $[4,5,6]$. However, recent evidence highlights to use universal charts, considering that the factors used in customization (ethnicity, age, weight and height) has minimal effect when fetal growth occurs in optimal environmental conditions [7]. This theory has been challenged following the recent publications, suggesting universal charts would be less sensitive than corresponding local charts in identifying small for gestational age (SGA) fetuses and adverse perinatal outcome [8,9]. Moreover, it is a matter of cost concern due to use of excess of fetal surveillance because of disproportionate number of fetuses being selected as SGA with the use of the universal charts [10].

Royal College of Obstetricians and Gynecologists guidelines recommend that women who are identified as

${ }^{1}$ North Colombo Teaching Hospital Ragama, ${ }^{2}$ Faculty of Medicine, University of Kelaniya, ${ }^{3}$ District General Hospital Ampara, Sri Lanka.

Correspondence: TD, e-mail: <thiran_dias@yahoo.com>. Received 22 August 2017, revised version received 13 May 2019 and accepted 16 June 2019.

This is an open-access article distributed under the terms of the Creative Commons Attribution License, which permits unrestricted use, distribution, and reproduction in any medium, provided the original author and source are credited. 
high risk for SGA should undergo serial ultrasound measurement with umbilical artery (UA) Doppler from 26 weeks onwards [11]. UA Doppler is used to assess fetal wellbeing in the late second trimester and third trimester of pregnancy. Uteroplacental insufficiency can be identified with increased resistance detected at umbilical arteries and it helps to identify high risk pregnancies. NICE guidelines recommend that women who are identified as high risk should be offered continuous electronic monitoring throughout labour [11].

Fetal middle cerebral arterial (MCA) Doppler is important in assessing fetal cardiovascular distress as well as fetal anemia. In late onset FGR, blood is preferentially diverted to the fetal brain in the expenses of fetal kidneys and bowels. Resistance of the flow of the middle cerebral artery is reduced in FGR and that could be reflected by reduced MCA (PI).

The Cerebral placental ratio (CPR) has recently been proposed as a marker of failure to reach growth potential at term, and abnormal CPR values have been linked to adverse perinatal outcomes [12]. There is no universal policy related to the use of Doppler to detect fetuses at risk of FGR in Sri Lanka. The aim of this study was to obtain normal values and their nomograms for UA and MCA pulsatility indices and CRP from 16 to 40 weeks for low risk pregnancies with normal BMI.

\section{Method}

This was a cross-sectional study carried out at Ampara district between January 2013 and January 2014. We enrolled women who initiated antenatal care before 14 weeks of gestation with normal nutritional and health status and minimal environmental constraints on fetal growth (Panel 1). Women who developed any obstetrics complications after the recruitment were excluded from the study. All pregnancies with first trimester ultrasound Crown- Rump Length (CRL) dating were included [13]. Inclusion criteria of the study population are given in Panel 1. Altman and Chitty have suggested that at least 300 observations would be necessary to get reasonable estimates [14]. The umbilical cord was visualized in longitudinal section in a free loop and magnified to the maximum possible extent in the absence of fetal movements or breathing. In all cases the angle of insonation was less than $60^{\circ}$. A transverse section of the fetal head was obtained and the colour box was applied to view the Circle of Willis and middle cerebral arteries.

The sampling gate was placed in the proximal MCA to obtain the Doppler waveform. All fetal Doppler measurements were obtained by a single certified operator (CG). CPR was calculated as the simple ratio between the MCA and the UA PI between 16 and 40 weeks. The mean differences in UA PI and MCA PI measurements between
Ampara women and data of Domenico et al, Italy were compared [14]. Standard errors (SE) of the means were calculated and compared for each gestational age between 20 and 40 weeks. Systematic error was assumed to exist if zero lay outside the mean difference \pm 2 SE. Linear and polynomial regression models were fitted separately to the means and standard deviations (SD) as functions of gestational age to identify the model with the best fit [14]. The centiles were obtained assuming that at each gestational age the measurements had a normal distribution. Altman and Chitty's statistical method [7] has been used to construct reference values and nomograms for MCA PI, UAPI and CPR. Approval was obtained from the Ethics Review Committee of the District General Hospital, Ampara. Informed written consent was obtained from all participants.

\section{Panel 1: Inclusion criteria used for selecting the study population}

- $\quad$ BMI $\geq 8.5$ and $<25 \mathrm{~kg} / \mathrm{m}^{2}$

- Singleton pregnancy

- Natural conception

- No relevant past medical history with no need for long term medication

- No evidence of socio-economic constraints likely to impede fetal growth

- No use of tobacco or recreational drugs, alcohol use

- No more than one miscarriage in the three previous consecutive pregnancies

- No previous baby delivered pre-term ( $<37$ weeks) or with a birth weight $<2500$ g or $>4500$ g

- No previous pregnancy affected by pre-eclampsia/ eclampsia, HELLP syndrome or a related pregnancyassociated condition

- No clinically significant atypical red cell alloantibodies

- No evidence of urinary tract infection or renal disease on urinalysis

- Systolic blood pressure $<140 \mathrm{mmHg}$ and diastolic blood pressure $<90 \mathrm{mmHg}$

- No diagnosis or treatment for anemia during this pregnancy

- Not in an occupation with risk of exposure to chemicals or toxic substances 


\section{Results}

We interviewed 2637 women at 11 weeks of gestation and only 596 (22.6\%) women were eligible for the study. Basic characteristics of the study group are given in Table 1. Tables 2 and 3 show the comparisons of the means and standard deviations of UA PI and MCA PI measurements obtained by the current study, compared with the data obtained from Domenico et al, Italy. Both the normal plot and the plot of the standardized residuals against gestation show that the data met the assumptions well. The reference centile values for UA PI, MCA PI and CPR are given in Table 4-6. The fitted centile charts of UA PI, MCA PI and CPR for each gestation are shown in Figure 1-3 respectively.
Table 1. Characteristics of the study population

\begin{tabular}{cc}
\hline \multicolumn{2}{c}{ Characteristic } \\
\hline Ethnicity (\%) \\
Sinhalese & $546(91.6)$ \\
Muslim & $39(6.5)$ \\
Tamil & $11(1.9)$ \\
Total & 596 \\
Parity $\quad$ Median & \\
(IQR) & $(1-2)$ \\
Mean Age in years & 28.4 \\
(SD) & $(5.1)$ \\
Mean BMI in kg/m ${ }^{2}$ & 21.45 \\
(SD) & $(2.1)$ \\
\hline
\end{tabular}

Table 2. Comparison of umbilical artery Pulsatility index (UA PI) data from Sri Lanka and Domenico et al, Italy

\begin{tabular}{|c|c|c|c|c|c|c|c|c|c|c|}
\hline \multirow[t]{2}{*}{$\begin{array}{c}\text { Gestational } \\
\text { age }\end{array}$} & \multicolumn{3}{|c|}{ Sri Lanka } & \multicolumn{3}{|c|}{$\begin{array}{c}\text { Domenico } \\
\text { et al }\end{array}$} & \multirow[t]{2}{*}{$\begin{array}{c}\text { Difference } \\
\text { of UA-PI }\end{array}$} & \multicolumn{3}{|c|}{ Estimated $95 \%$ CI } \\
\hline & $\begin{array}{c}\text { Number } \\
\text { of } \\
\text { fetuses }\end{array}$ & $\begin{array}{c}\text { Mean } \\
U A \\
P I\end{array}$ & $S D$ & $\begin{array}{c}\text { Number } \\
\text { of } \\
\text { fetuses }\end{array}$ & $\begin{array}{c}\text { Mean } \\
U A \\
P I\end{array}$ & $S D$ & & & & \\
\hline 20 & 34 & 1.26 & 0.37 & 80 & 1.54 & 0.301 & -0.28 & -0.41 & to & $-0.15^{*}$ \\
\hline 21 & 26 & 1.20 & 0.32 & 48 & 1.47 & 0.301 & -0.27 & -0.41 & to & $-0.13^{*}$ \\
\hline 22 & 27 & 1.15 & 0.28 & 60 & 1.41 & 0.301 & -0.26 & -0.40 & to & $-0.12^{*}$ \\
\hline 23 & 19 & 1.11 & 0.25 & 60 & 1.35 & 0.301 & -0.24 & -0.39 & to & $-0.09^{*}$ \\
\hline 24 & 30 & 1.07 & 0.22 & 50 & 1.30 & 0.301 & -0.23 & -0.36 & to & $-0.10^{*}$ \\
\hline 25 & 25 & 1.03 & 0.20 & 60 & 1.25 & 0.301 & -0.22 & -0.35 & to & $-0.09^{*}$ \\
\hline 26 & 27 & 1.00 & 0.18 & 105 & 1.20 & 0.301 & -0.20 & -0.32 & to & $-0.08^{*}$ \\
\hline 27 & 20 & 0.98 & 0.17 & 135 & 1.16 & 0.301 & -0.18 & -0.32 & to & $-0.04^{*}$ \\
\hline 28 & 24 & 0.96 & 0.16 & 120 & 1.12 & 0.301 & -0.16 & -0.29 & to & $-0.03^{*}$ \\
\hline 29 & 13 & 0.94 & 0.16 & 80 & 1.08 & 0.301 & -0.14 & -0.31 & to & 0.03 \\
\hline 30 & 16 & 0.93 & 0.16 & 75 & 1.05 & 0.301 & -0.12 & -0.27 & to & 0.03 \\
\hline 31 & 18 & 0.92 & 0.16 & 60 & 1.02 & 0.301 & -0.10 & -0.25 & to & 0.05 \\
\hline 32 & 24 & 0.91 & 0.16 & 75 & 0.99 & 0.301 & -0.08 & -0.21 & to & 0.05 \\
\hline 33 & 25 & 0.91 & 0.16 & 65 & 0.97 & 0.301 & -0.06 & -0.19 & to & 0.07 \\
\hline 34 & 36 & 0.90 & 0.17 & 70 & 0.95 & 0.301 & -0.05 & -0.16 & to & 0.06 \\
\hline 35 & 25 & 0.90 & 0.17 & 70 & 0.94 & 0.301 & -0.04 & -0.17 & to & 0.09 \\
\hline 36 & 22 & 0.89 & 0.17 & 60 & 0.92 & 0.301 & -0.03 & -0.17 & to & 0.11 \\
\hline 37 & 30 & 0.89 & 0.18 & 75 & 0.92 & 0.301 & -0.03 & -0.15 & to & 0.09 \\
\hline 38 & 23 & 0.88 & 0.18 & 65 & 0.91 & 0.301 & -0.03 & -0.16 & to & 0.10 \\
\hline 39 & 07 & 0.88 & 0.17 & 40 & 0.91 & 0.301 & -0.03 & -0.27 & to & 0.21 \\
\hline 40 & 32 & 0.87 & 0.17 & 35 & 0.91 & 0.301 & -0.04 & -0.16 & to & 0.08 \\
\hline
\end{tabular}

* The differences between values were significant if zero lay outside the estimated 95\% CI in two populations (SD - standard deviation) 
Table 3. Comparison of Middle cerebral artery Pulsatility index (MCA PI) data from Sri Lanka and Domenico et al, Italy

\begin{tabular}{|c|c|c|c|c|c|c|c|c|c|c|}
\hline \multirow[t]{2}{*}{$\begin{array}{c}\text { Gestational } \\
\text { age }\end{array}$} & \multicolumn{3}{|c|}{ Sri Lanka } & \multicolumn{3}{|c|}{$\begin{array}{l}\text { Domenico } \\
\quad \text { et al }\end{array}$} & \multirow[t]{2}{*}{$\begin{array}{c}\text { Difference of } \\
\text { MCA-PI }\end{array}$} & \multicolumn{3}{|c|}{ EstimatedCI } \\
\hline & $\begin{array}{l}\text { Number } \\
\text { of } \\
\text { fetuses }\end{array}$ & $\begin{array}{c}\text { Mean } \\
\text { MCA- } \\
\text { PI }\end{array}$ & $S D$ & $\begin{array}{l}\text { Number } \\
\text { of } \\
\text { fetuses }\end{array}$ & $\begin{array}{c}\text { Mean } \\
\text { MCA- } \\
\text { PI }\end{array}$ & $S D$ & & & & \\
\hline 20 & 34 & 2.45 & 0.67 & 80 & 1.83 & 0.289 & 0.62 & 0.44 & to & $0.80^{*}$ \\
\hline 21 & 26 & 2.50 & 0.65 & 48 & 1.87 & 0.289 & 0.63 & 0.41 & to & $0.85^{*}$ \\
\hline 22 & 27 & 2.55 & 0.64 & 60 & 1.91 & 0.289 & 0.64 & 0.44 & to & $0.84^{*}$ \\
\hline 23 & 19 & 2.58 & 0.64 & 60 & 1.93 & 0.289 & 0.65 & 0.44 & to & $0.86^{*}$ \\
\hline 24 & 30 & 2.61 & 0.64 & 50 & 1.96 & 0.289 & 0.65 & 0.44 & to & $0.86^{*}$ \\
\hline 25 & 25 & 2.62 & 0.65 & 60 & 1.97 & 0.289 & 0.65 & 0.45 & to & $0.85^{*}$ \\
\hline 26 & 27 & 2.61 & 0.66 & 105 & 1.98 & 0.289 & 0.63 & 0.46 & to & $0.80^{*}$ \\
\hline 27 & 20 & 2.60 & 0.68 & 135 & 1.99 & 0.289 & 0.61 & 0.44 & to & $0.78^{*}$ \\
\hline 28 & 24 & 2.57 & 0.69 & 120 & 1.99 & 0.289 & 0.58 & 0.41 & to & $0.75^{*}$ \\
\hline 29 & 22 & 2.53 & 0.71 & 80 & 1.99 & 0.289 & 0.54 & 0.34 & to & $0.74^{*}$ \\
\hline 30 & 16 & 2.48 & 0.72 & 75 & 1.98 & 0.289 & 0.50 & 0.28 & to & $0.72^{*}$ \\
\hline 31 & 17 & 2.42 & 0.72 & 60 & 1.97 & 0.289 & 0.45 & 0.22 & to & $0.68^{*}$ \\
\hline 32 & 24 & 2.35 & 0.72 & 75 & 1.95 & 0.289 & 0.40 & 0.20 & to & $0.60^{*}$ \\
\hline 33 & 25 & 2.26 & 0.71 & 65 & 1.93 & 0.289 & 0.33 & 0.12 & to & $0.54^{*}$ \\
\hline 34 & 34 & 2.16 & 0.70 & 70 & 1.90 & 0.289 & 0.26 & 0.07 & to & $0.45^{*}$ \\
\hline 35 & 25 & 2.05 & 0.67 & 70 & 1.86 & 0.289 & 0.19 & -0.01 & to & 0.39 \\
\hline 36 & 23 & 1.93 & 0.63 & 60 & 1.82 & 0.289 & 0.11 & -0.09 & to & 0.31 \\
\hline 37 & 29 & 1.80 & 0.57 & 75 & 1.78 & 0.289 & 0.02 & -0.15 & to & 0.19 \\
\hline 38 & 23 & 1.65 & 0.50 & 65 & 1.73 & 0.289 & 0.08 & -0.25 & to & 0.09 \\
\hline 39 & 07 & 1.49 & 0.41 & 40 & 1.67 & 0.289 & 0.18 & 0.57 & to & $1.07^{*}$ \\
\hline 40 & 32 & 1.32 & 0.31 & 35 & 1.61 & 0.289 & 0.29 & 0.56 & to & $0.86^{*}$ \\
\hline
\end{tabular}

${ }^{*}$ The differences between values were significant if zero lay outside the estimated 95\% CI in two populations (SD - standard deviation) 
Table $4.10^{\text {th }}, 50^{\text {th }}$ and $90^{\text {th }}$ centiles of Umbilical artery pulsatility index,

Middle cerebral artery pulsatility index and cerebral placental ratio at each gestation between 16 and 40 weeks in all the women with normal BMI $(n=596)$

\begin{tabular}{|c|c|c|c|c|c|c|c|c|c|c|c|c|c|}
\hline \multirow{2}{*}{$\begin{array}{c}\text { Gestational } \\
\text { age } \\
\text { (weeks) }\end{array}$} & \multirow{2}{*}{$\begin{array}{c}\text { Number } \\
\text { of } \\
\text { fetuses }\end{array}$} & \multicolumn{4}{|c|}{$\begin{array}{l}\text { Umbilical artery } \\
\text { pulsatility index }\end{array}$} & \multicolumn{4}{|c|}{$\begin{array}{c}\text { Middle cerebral artery } \\
\text { pulsatility index }\end{array}$} & \multicolumn{4}{|c|}{ Cerebral placental ratio } \\
\hline & & $\begin{array}{c}10^{\text {th }} \\
\text { centile }\end{array}$ & $\begin{array}{c}50^{\text {th }} \\
\text { centile }\end{array}$ & $\begin{array}{c}90^{t h} \\
\text { centile }\end{array}$ & $S D$ & $\begin{array}{c}10^{\text {th }} \\
\text { centile }\end{array}$ & $\begin{array}{c}50^{\text {th }} \\
\text { centile }\end{array}$ & $\begin{array}{c}90^{\text {th }} \\
\text { centile }\end{array}$ & $S D$ & $\begin{array}{c}10^{\text {th }} \\
\text { centile }\end{array}$ & $\begin{array}{c}50^{\text {th }} \\
\text { centile }\end{array}$ & $\begin{array}{c}90^{\text {th }} \\
\text { centile }\end{array}$ & $S D$ \\
\hline 16 & 26 & 0.74 & 1.59 & 2.44 & 0.66 & 0.97 & 2.09 & 3.21 & 0.87 & 0.55 & 1.32 & 2.09 & 0.60 \\
\hline 17 & 20 & 0.76 & 1.49 & 2.23 & 0.58 & 1.17 & 2.20 & 3.23 & 0.80 & 0.76 & 1.54 & 2.31 & 0.61 \\
\hline 18 & 19 & 0.77 & 1.41 & 2.05 & 0.50 & 1.34 & 2.29 & 3.24 & 0.74 & 0.94 & 1.74 & 2.53 & 0.62 \\
\hline 19 & 26 & 0.78 & 1.33 & 1.89 & 0.43 & 1.48 & 2.38 & 3.27 & 0.70 & 1.10 & 1.92 & 2.74 & 0.64 \\
\hline 20 & 34 & 0.79 & 1.26 & 1.74 & 0.37 & 1.59 & 2.45 & 3.30 & 0.67 & 1.23 & 2.08 & 2.93 & 0.66 \\
\hline 21 & 26 & 0.79 & 1.20 & 1.62 & 0.32 & 1.67 & 2.50 & 3.33 & 0.65 & 1.34 & 2.22 & 3.11 & 0.69 \\
\hline 22 & 27 & 0.79 & 1.15 & 1.51 & 0.28 & 1.73 & 2.55 & 3.37 & 0.64 & 1.42 & 2.35 & 3.28 & 0.72 \\
\hline 23 & 19 & 0.79 & 1.11 & 1.42 & 0.25 & 1.77 & 2.58 & 3.40 & 0.64 & 1.49 & 2.46 & 3.43 & 0.76 \\
\hline 24 & 30 & 0.78 & 1.07 & 1.35 & 0.22 & 1.78 & 2.61 & 3.43 & 0.64 & 1.54 & 2.55 & 3.56 & 0.79 \\
\hline 25 & 25 & 0.78 & 1.03 & 1.28 & 0.20 & 1.78 & 2.62 & 3.45 & 0.65 & 1.57 & 2.62 & 3.68 & 0.82 \\
\hline 26 & 27 & 0.77 & 1.00 & 1.23 & 0.18 & 1.76 & 2.61 & 3.46 & 0.66 & 1.59 & 2.68 & 3.77 & 0.85 \\
\hline 27 & 20 & 0.76 & 0.98 & 1.20 & 0.17 & 1.73 & 2.60 & 3.47 & 0.68 & 1.59 & 2.72 & 3.84 & 0.88 \\
\hline 28 & 24 & 0.75 & 0.96 & 1.17 & 0.16 & 1.69 & 2.57 & 3.46 & 0.69 & 1.58 & 2.74 & 3.89 & 0.90 \\
\hline 29 & 22 & 0.74 & 0.94 & 1.14 & 0.16 & 1.63 & 2.53 & 3.44 & 0.71 & 1.56 & 2.74 & 3.92 & 0.92 \\
\hline 30 & 16 & 0.73 & 0.93 & 1.13 & 0.16 & 1.57 & 2.48 & 3.40 & 0.72 & 1.53 & 2.72 & 3.92 & 0.93 \\
\hline 31 & 17 & 0.72 & 0.92 & 1.12 & 0.16 & 1.50 & 2.42 & 3.35 & 0.72 & 1.49 & 2.69 & 3.89 & 0.93 \\
\hline 32 & 24 & 0.71 & 0.91 & 1.12 & 0.16 & 1.42 & 2.35 & 3.27 & 0.72 & 1.45 & 2.64 & 3.83 & 0.93 \\
\hline 33 & 25 & 0.70 & 0.91 & 1.12 & 0.16 & 1.35 & 2.26 & 3.18 & 0.71 & 1.40 & 2.57 & 3.74 & 0.91 \\
\hline 34 & 34 & 0.69 & 0.90 & 1.12 & 0.17 & 1.27 & 2.16 & 3.06 & 0.70 & 1.34 & 2.48 & 3.62 & 0.89 \\
\hline 35 & 25 & 0.68 & 0.90 & 1.12 & 0.17 & 1.20 & 2.05 & 2.91 & 0.67 & 1.29 & 2.37 & 3.46 & 0.85 \\
\hline 36 & 23 & 0.67 & 0.89 & 1.12 & 0.17 & 1.13 & 1.93 & 2.73 & 0.63 & 1.23 & 2.25 & 3.27 & 0.80 \\
\hline 37 & 29 & 0.66 & 0.89 & 1.11 & 0.18 & 1.06 & 1.80 & 2.53 & 0.57 & 1.17 & 2.11 & 3.04 & 0.73 \\
\hline 38 & 23 & 0.66 & 0.88 & 1.11 & 0.18 & 1.01 & 1.65 & 2.29 & 0.50 & 1.12 & 1.95 & 2.78 & 0.65 \\
\hline 39 & 07 & 0.65 & 0.88 & 1.10 & 0.17 & 0.96 & 1.49 & 2.02 & 0.41 & 1.07 & 1.77 & 2.48 & 0.55 \\
\hline 40 & 32 & 0.65 & 0.87 & 1.08 & 0.17 & 0.93 & 1.32 & 1.71 & 0.31 & 1.02 & 1.58 & 2.13 & 0.43 \\
\hline
\end{tabular}




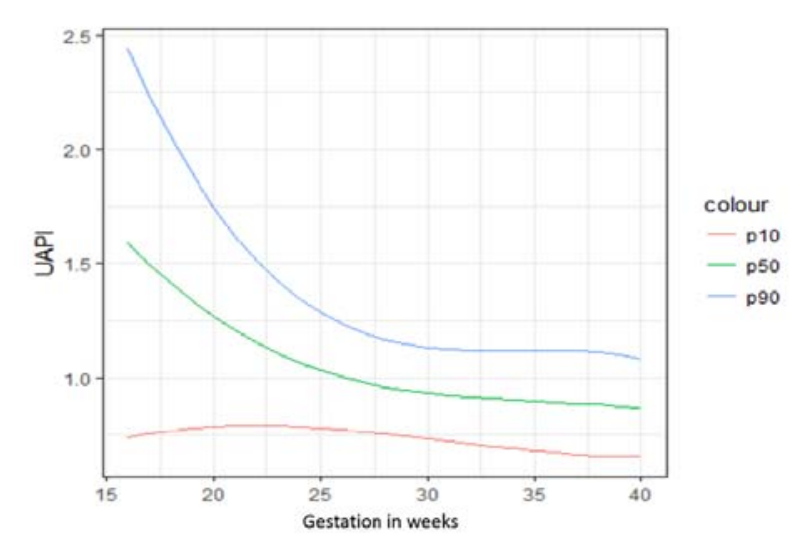

Figure 1. Umbilical artery Pulsatility index (UA PI) centile charts $\left(p 10-10^{\text {th }}\right.$ centile, p50 $-50^{\text {th }}$ centile, p90 $-90^{\text {th }}$ centile).

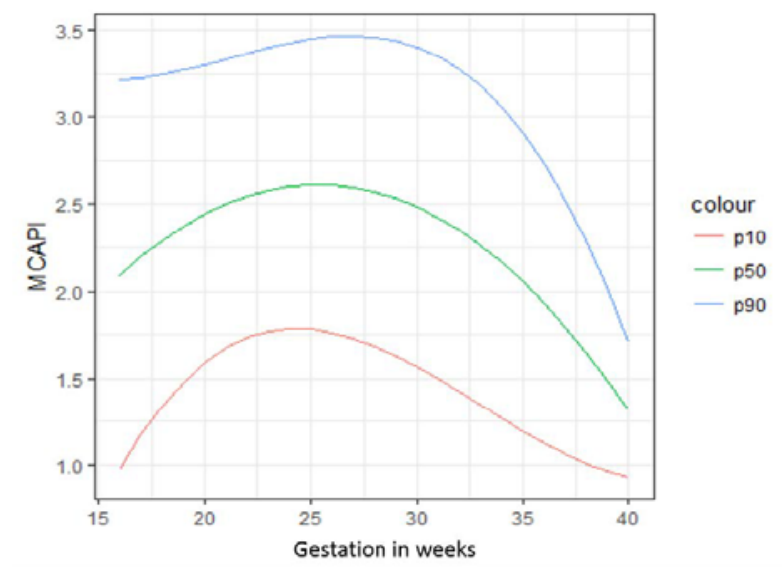

Figure 2. Middle cerebral artery Pulsatility index (MCA PI) centile charts (p10 - 10 centile, $\mathrm{p} 50-50^{\text {th }}$ centile, $\mathrm{p} 90-90^{\text {th }}$ centile).

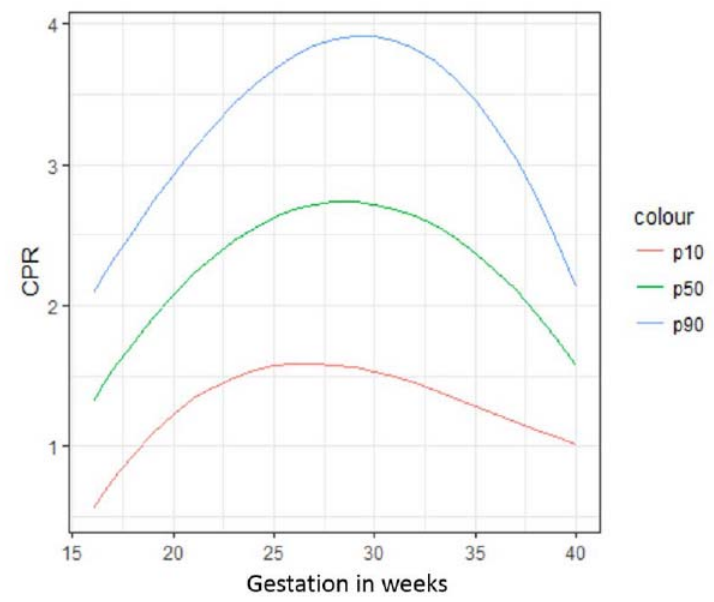

Figure 3. Cerebral Placental ratio (CPR) centile charts $\left(\mathrm{p} 10-10^{\text {th }}\right.$ centile, p50 $-50^{\text {th }}$ centile, p90 $-90^{\text {th }}$ centile).

\section{Discussion}

Both accurate assessment and rational interpretation of fetal Doppler measurements are important in the management of fetal growth restriction. Inadvertent interpretation of Doppler indices puts fetus at risk of increased morbidity/ mortality and unwanted early interventions. Our study demonstrated that fetal Doppler indices of singleton fetuses in pregnant women with normal nutritional and health status in the Ampara district were significantly different from the routinely used reference charts. Importantly, assessment of umbilical artery Doppler in FGR is most useful before 34 weeks as placental resistance tends to be low in late gestations and it may hinder the accuracy. We demonstrated notable systematic differences in umbilical artery PI that before 34 weeks in two studies. Furthermore, MCA PI is more reliable at term, whereas systematic differences between two studies were more in MCA PI at term. We have developed new gestational age based reference ranges of Doppler indices between 16 and 40 weeks of gestation for normal BMI Sri Lankan population.

The CPR represents the refection of changes in cerebral blood flow as indicated by increased diastolic flow. It is characterized by cerebrovascular dilation resulting from hypoxia and increased placental resistance, resulting in decreased diastolic flow of the umbilical artery. An abnormal CPR (CPR $<10^{\text {th }}$ centile) could be resulted due to three types of Doppler measurement patterns. Firstly, when the UA PI and MCA PI are in the upper and lower range of the distribution curve respectively. Secondly, when the UA PI is normal, but the MCA PI is decreased, thirdly, an abnormally elevated UA PI and an abnormally decreased MCA PI. The CPR has been proposed recently as a marker of failure to reach growth potential at term, and abnormal CPR values have been linked to adverse perinatal outcome, including cesarean section for fetal compromise, abnormal intrapartum monitoring and admission to the neonatal unit. Those fetuses affected with failure to reach the genetic growth potential may present low CPR values independently of their weight centile $[16,17,18,19,20,21]$ Our new CPR charts for Sri Lankan population could be used now to assess fetuses at risk of failure to achieve growth potential.

The main strength of our study is that we managed to recruit women having normal nutritional and health status, minimal environmental constraints on fetal growth and women did not develop any obstetrics complications in addition to normal BMI. Moreover, we were able to determine the gestational age between 11 and 14 weeks using fetal crown-rump length in all subjects. This has resulted in the elimination of dating bias. Moreover, we have adopted an internationally accepted technique to acquire Doppler measurements and measurements were supervised by an accredited operator. We have constructed new reference ranges for UA PI, MCA PI and CPR between 20 and 40 weeks. Comparability of most previously published data is limited by methodological 
and technical characteristics. We have designed a crosssectional study in which each fetus was measured once compared to longitudinal design in which more likely to result in biased estimates and require more complex statistical models than cross-sectional studies. Furthermore, we have used statistical methods that considered the varying variability of the measurements with increasing gestational age in the construction of the centile charts, and we have carefully assessed the goodness of fit of the models obtained.

The main limitations of our study were failure to obtain multiple measurements to assess intra observer variations in obtaining the fetal Doppler indices. Assessment of repeatability had been more difficult due to the paucity of equipment and certified obstetricians. Our data need to be validated in a multicenter study in order to improve the generalizability.

Simplified charts for fetal Doppler indices have immense value as it is difficult to have individually customized charts in low resource setting. In conclusion, our study has shown that fetal Doppler indices of singleton fetuses in pregnant women with normal nutritional and health status in the Ampara district were significantly different from a routinely used reference chart. We have presented new centile charts for fetal Doppler indices derived from a carefully designed prospective cross-sectional study.

\section{Conflict of interests}

None.

\section{References}

1. Zarko Alfirevic, Tamara Stampalija, Gillian ML Gyte. Fetal and umbilical Doppler ultrasound in high-risk pregnancies. Cochrane Database Syst Rev.2010. https:// www.ncbi.nlm.nih.gov/pmc/articles/PMC4167858/ (accessed on May 07, 2017)

2. National Collaborateing center for Women's and Children's Health. Antenatal Care: Routine Care for the Healthy Prgnant woman. National Institute for Clinical Excellence, 2008.

3. Palacio M, Figueras F, Zamora L, Jiménez JM, Puerto B, Coll O, Cararach V, Vanrell JA. Ultrasound in Obstetrics and Gynecology 2004; 24: 647-53.

4. Gardosi J. Ethnic differences in fetal growth. Ultrasound in Obstetrics and Gynecology 1995; 6: 73-4.

5. Kandraju H, Agrawal S, Geetha K, Sujatha L, Subramanian S, Murki S. Gestational Age-specific Centile Charts for Anthropometry at Birth for South Indian Infants. Indian Pediatrics 2012; 49: 199-202.

6. Gardosi J. Customised assessment of fetal growth potential: implications for perinatal care. Archives of Disease in Childhood Fetal Neonatal Ed 2012; 97: F 314-7.

7. Villar J, Altman DG, Purwar M, Noble JA, Knight HE, Ruyan P, Cheikh Ismail L, Barros FC, Lambert A, Papageorghiou AT, Carvalho M, Jaffer YA, Bertino E,
Gravett MG, Bhutta ZA, Kennedy SH; International Fetal and Newborn Growth Consortium for the 21st Century. The objectives, design and implementation of the INTERGROWTH-21st Project. British Journal of Obstetrics and Gynaecology 2013; 120 Suppl 2: 9-26,

8. Anderson NH, Sadler LC, McKinlay CJ, McCowan LM. INTERGROWTH-21st vs customized birthweight standards for identification of perinatal mortality and morbidity. American Journal of Obstetrics and Gynecology 2016; 214: 509.

9. Poon LC, Tan MY, Yerlikaya G, Syngelaki A, Nicolaides $\mathrm{KH}$. Birth weight in live births and stillbirths. Ultrasound in Obstetrics and Gynecology 2016; 48: 602-6.

10. Cheng Y, Leung TY, Lao T, Chan YM, Sahota DS. Impact of replacing Chinese ethnicity-specific fetal biometry charts with the INTERGROWTH-21(st) standard. British Journal of Obstetrics and Gynaecology 2016; 123 Suppl 3: 48-55.

11. Royal College of Obstetricians and Gynaecologists. GreenTop Guidline No.31, The Investigation and Management of the Small-for-Gestational-Age Fetus 2013.

12. Khalil AA, Morales-Rosello J, Elsaddig M, Khan N, Papageorghiou A, Bhide A, Thilaganathan B. The association between fetal Doppler and admission to neonatal unit at term American Journal of Obstetrics and Gynecology 2015; 213: 1-7.

13. Dias T, Abeykoon S, Kumarasiri S, Gunawardena C, Pragasan G, Padeniya T, Pathmeswaran A. Symphysispubis fundal height charts to assess fetal size in women with a normal body mass index. Ceylon Medical Journal 2016; 61: 106-12.

14. Altman DG, Chitty LS. Charts of fetal size: 1. Methodology. British Journal of Obstetrics and Gynaecology 1994; 101(1): 29-34.

15. Domenico A, Giuseppe R. Normal values of Pulsatility Index front fetal vessels: A cross-sectional study on 1556 healthy fetuses. Journal of Perinatal Medicine 1990; 18: 165-72.

16. Morales-Roselló J, Khalil A. Fetal cerebroplacental ratio and adverse perinatal outcome. Journal of Perinatal Medicine 2016; 44: 355.

17. Morales-Roselló J, Khalil A. Fetal cerebral redistribution: a marker of compromise regardless of fetal size. Ultrasound in Obstetrics and Gynecology 2015; 46: 385-8.

18. Khalil A, Morales-Roselló J, Townsend R, Morlando M, Papageorghiou A, Bhide A, Thilaganathan B. Value of thirdtrimester cerebroplacental ratio and uterine artery Doppler indices as predictors of stillbirth and perinatal loss. Ultrasound in Obstetrics and Gynecology 2016; 47: 74-80.

20. Khalil A, Morales-Rosello J, Morlando M, Hannan H, Bhide A, Papageorghiou A, Thilaganathan B. Is fetal cerebroplacental ratio an independent predictor of intrapartum fetal compromise and neonatal unit admission? American Journal of Obstetrics and Gynecology 2015; 213: 54.

21. Morales-Roselló J, Khalil A, Morlando M, Bhide A, Papageorghiou A, Thilaganathan B. Poor neonatal acidbase status in term fetuses with low cerebroplacental ratio. U Ultrasound in Obstetrics and Gynecology 2015; 45 : 156-61. 